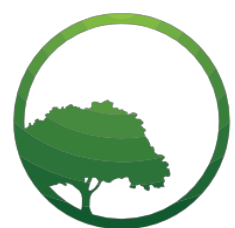

Business \& Social Science IJRBS

\section{Research in Business and Social Science}

IJRBS Vol 7 No 4, ISSN: 2147-4478

Contents available at www.ssbfnet.com/ojs

\title{
Supervisor Workplace Gossip and Employee Job Performance: The Mediation Effect of Employee Job Engagement
}

\section{Phakamani Dlamani}

Corresponding Author: Phd., School of Business and Management, Huazhong University of Science and Technology

\section{Iris Zhou}

Prof, School of Business and Management, Huazhong University of Science and Technology

\section{Juniter Kwamboka}

PhD., School of Business and Management, Huazhong University of Science and Technology

\begin{abstract}
This paper examined the role of supervisor gossip on subordinate job performance. The paper hypothesized that supervisor's negative and positive gossip influence employee job engagement which in subsequently affects employee job performance. Dyadic research design was used to collect data from a sample of 228 employees and supervisors from Kwa Zulu Natal Government Municipality, South Africa. The employees completed the questionnaire items on supervisor gossip and job engagement, while their supervisors completed the questionnaire items on employee job performance. Data collection was done in three waves. The study established that positive superior gossip positively and significantly influenced employee job engagement, which positively improved employee job performance; while negative superior gossip had a positive, but insignificant effect on employee job engagement. The study was limited by the multicultural nature of the municipality as well as the causality issues and common method biases associated with research design. Having managed to utilize Social Exchange Theory (SET) in disentangling the supervisor-subordinate reciprocal communication web, the study proposes that supervisors should inculcate effective strategies of utilizing both positive and negative gossip in the workplace so as to increase positive employee outcomes. Negative gossip will cause tension, stress and mistrust among employees, while positive gossip will lead to creation of workplace antagonism and competition. This study attempted to assess the implication of supervisor gossip on employee job engagement and performance in the public service sector, whose employees are characterized with high job security as compared to their peers in the private sector.
\end{abstract}

Key words: Supervisor gossip, Job engagement, Mediator, job performance, Public sector JEL classification: $015, P 36$

Submitted: 14.09.2018 - Accepted: 19.10.2018 


\section{Introduction}

Workplace gossip occurs when one member of the organization (the gossiper) engages in an informal and evaluative communication with another member(s) (the gossip recipient), about a third member who is possibly absent during the gossip(the victim)(Beersma \& Van Kleef, 2012; Kurland \& Pelled, 2000). Workplace gossip is a naturally occurring social phenomena which affects minds, deeds and hearts of people(Beersma \& Van Kleef, 2012). It is a research field of organization behavior and psychology(Brady, Brown, \& Liang, 2017), which has attracted attention of many scholars(Beersma \& Van Kleef, 2012). Therefore, understanding its implication to organizational outcomes is vital, considering that up to about $65 \%$ of peoples' time in organizations is spent on discussions on social topics, of which up to a third is about third parties(Dunbar, 2004). Considerable progress has been made on the influence of gossip to organizations workplace behaviors (Mills, 2010). Interdisciplinary evidence alludes that workplace gossip enhances social bonding and power creation and struggle (Baumeister, Zhang, \& Vohs, 2004) and information management, interpersonal trust, and norm learning(Brady et al., 2017). By and large, workplace gossip has been reported to affect employee workplace orientation and behaviors(Kuo, Chang, Quinton, Lu, \& Lee, 2015). Despite this evidence, scholarly work on effects of superior gossip on subordinate reactions, particularly on employee engagement and ultimate job performance in a public sector setting, remains scanty, incomplete, or with mixed findings.

This study contributed immensely to the literature on gossip. First, it restricted employee engagement to only job engagement, and incorporated it into the study in trying to establish the effect of perceived superior gossip on job performance in the public sector. This enabled the study to be restricted to employee level by leaving out organizational engagement which is occasionally used in tandem with organization citizenship behavior(Wu, Birtch, Chiang, \& Zhang, 2016). Secondly, the both positive and negative superior gossip were explored in establishing how they interrelate with job engagement to influence employee job performance. By focusing on both negative and positive superior gossip, it helped in finding out how superior gossip diminishes or exacerbates victims' job engagement and job performance in the public sector, whose employees enjoy higher job security than those from the private sector.

\section{Literature Review}

\section{Supervisor Workplace Gossip}

Supervisor workplace gossip occurs when supervisors informally discuss subordinates in their absence. In most cases, the superiors either positively, or negatively discuss workplace conduct of their subordinates with respect to knowledge and abilities(Kuo, Wu, \& Lin, 2018), workplace behaviors and attitudes(Kuo et al., 2015), and job performance Evaluations(Traylor, 2008). Supervisor gossip, just like any other form of workplace gossip must meet some threshold of workplace gossip. As per Kurland and Pelled (2000), the gossip must take place within a social setting (organization), it must be targeted towards individuals within the organization, must be evaluative in nature, and the target or victim should be known to the gossiper, and only the gossiper knows the subject of gossip. In addition, some scholars have suggested a vital component of the gossip web: that the gossip usually takes place in the absence of the victim, thus making it difficult for the victim to establish the source of the gossip or to substantiate the authenticity of the contents of the gossip(Wu et al., 2016). However, with supervisor negative or positive gossip, the web is clear: it is the supervisor gossiping the subordinates regarding their work attributes and behaviors, or performance(Kuo et al., 2015). Positive supervisor gossip encompasses positive remarks made by supervisor about their subordinates regarding accomplishment of a difficult job-related task, an impending promotions, exemplary workplace behavior and conduct, and a workplace achievement(Brady et al., 2017).

Supervisor negative gossip occurs when supervisor discuss their subordinates concerning their decline in job performance, lethargic workplace attitudes and interpersonal relations as well as their level of organization citizen behavior (Wu et al., 2016). Subordinates desire positive supervisor gossip to negative one(Baumeister et al., 2004), since they perceive it as a form of performance feedback from the supervisor(Brady et al., 2017), while negative supervisor is perceived as a form of sanction which increases employee workplace stress, negative affectivity, and reduced employee leader member exchange 
(LMX)(Restubog, Bordia, Tang, \& Krebs, 2010). Superior negative gossip may increase loci of control for employees, increasing their self-interrogation and regulation in relation to job requirements( $\mathrm{Wu}$, Birtch, Chiang, \& Zhang, 2018). Therefore, both positive and negative supervisor gossip may affect subordinate workplace behaviors, with employee engagement being one of them.

\section{Employee Engagement}

Employee engagement has received mixed treatment by many organizational behavior researchers, due unclear delink from constructs like organizational citizenship behavior and employee commitment(Robinson, Perryman, \& Hayday, 2004; Utaminingsih \& Purnomo, 2017). Many scholars have described employee engagement in many ways: The definition by Robinson et al. (2004), demonstrates employee engagement as an amount of discretionary effort employees exhibit in their jobs, while Kahn (1990), defines employee engagement as "the act of harnessing of organization members' selves to their work roles", suggesting that engaged employees express themselves, emotionally, physically, and even cognitively during role performances. With clarity, Kahn (1990), reiterates that engaged employees must be psychologically present when performing an organizational role. This psychological presence is what he termed as engagement. Kahn (1990), therefore suggested three conditions that are associated with employee engagement or disengagement at work: meaningfulness, safety, and availability. In other words, (Kahn, 1990) implied that employees engaged more in work when they are more psychologically available or in situations that offer them more psychological safety. An improvement to Kahn (1990)'s definition of engagement was offered by Rothbard (2001), who emphasized on cognitive availability as well as the amount of time an employee spends thinking about a job related roles(attention), and the intensity of one's focus on the role (absorption), as key components of engaged employees other than psychological presence. Therefore, job engagement is the degree to which an employee is absorbed and attentive in performing their job roles but not is not an attitude or an opinion towards the job roles(Maslach, Schaufeli, \& Leiter, 2001; Robinson et al., 2004), and in addition to their cognitions, it involves active use of emotions and behaviors (Saks, 2006). Utaminingsih and Purnomo (2017), describes it as the antithesis of burn-out. This makes it different from employees' organizational commitment, which implies employee attitude and attachment towards their organizations; and organizational citizenship behavior (OCB), which involves voluntary and informal behaviors that can help employees and other co-workers as well as the organization(Saks, 2006). Therefore, to be engaged in the workplace is more of formal role performance rather than extra-role or voluntary behavior in the workplace. Finally, engagement is not job involvement. One's job involvement is one's cognitive judgement about the job's ability to satisfy their needs (May, Gilson, \& Harter, 2004). Conversely, May et al. (2004), alludes that engagement maybe treated as an antecedent to job involvement and that individuals who experience deep engagement in their roles which will subsequently improve their job performance(Siddiqui, Sauer, \& Baker, 2004), how they identify with their jobs, and this will be ultimately be reflected in their job performance. Therefore, any aspect of the workplace that has to do with how individuals conduct themselves in their job, will influence their engagement in that job. How that will affect employee job performance is the subject for this study.

\section{Supervisor workplace Gossip and Employee engagement.}

The conduct of the supervisor in the work place, especially from the perspective of fellow supervisors or subordinates will have many workplace effects. Evidence on employee's job engagement suggests that highly engaged employees express themselves physically, emotionally, and even cognitively while performing their roles. This expression is driven by their need to meet job requirements and targets (Kahn, 1990). Scanty academic literature exists on the relationship between supervisors' gossip and employee's engagement. To unfold this dyadic relationship, supervisor workplace gossip was examined from the perspective of the victim, especially in the case of negative supervisor gossip. Similarly, employees perceive positive supervisor gossip as a source of psychological motivation(Kuo et al., 2015), especially if the gossip concerns employee performance in job tasks, goals, and objectives(Saks, 2006). The positive gossip will act as a recognition of employees' efforts which will increase their task contentment and desire to achieve more. May et al. (2004), intimated that rewarding of co-workers and a supportive supervisor relations were positive predictors of employee's feeling of safety and absorption to their job roles. 
Psychological safety involves a sense of being able to show and employ the self without negative consequences (Kahn, 1992). Both positive and negative supervisor gossip will interfere with employee psychological safety(Bosson, Johnson, Niederhoffer, \& Swann, 2006). The comments that the supervisor may make regarding employee conduct in the line of duty will affect the psychological contentment of the employee in the workplace(Utaminingsih \& Purnomo, 2017). This in turn will shape employee relationship with their supervisor and ultimately increase or reduce their absorption to the job tasks. Therefore, a positive supervisor gossip specifically on employee job effectiveness, will acts as a motivational reward or resource to the employees, which will confer reciprocal responsibility on the part of the employee to pay back through excellence in the job tasks. This absorption will increase employee engagement though the degrees will vary from employee to employee(Robinson et al., 2004). However, some evidence alludes that it is more difficult for employees to vary their levels of job performance as a result of gossip given that their job performance is often evaluated and used as the basis for job compensation. (Saks, 2006). Conversely, negative supervisor gossip can be simultaneously spread by supervisors in the workplace and may increase or decrease employee job engagement(Bosson et al., 2006).

Bosson et al. (2006), observed that supervisor positive gossip will increase interpersonal trust among employees or among employees and their supervisors which increases their desire to achieve more. On the other hand, Bosson et al. (2006) indicated that negative gossip is associated with fear and prevention focus among employees which eventually cultivate trust, and strengthen intimate employee social bonds outside the workplace. This trust and intimate social bonds will obviously increase employee teamwork (Bosson et al., 2006; Harter, Schmidt, \& Hayes, 2002), which will strengthen their focus on job roles. Subsequently, this paper proposes that negative superior gossip may be perceived by employees as a sanction from the supervisor which may increase the psychological distance between subordinates and supervisors, hence minimizing employee disengagement from job roles, whereas positive supervisor gossip increases employee engagement to their job roles.

\section{H1- Perceived positive superior gossip is positively associated with employee job engagement.}

H2- Perceived negative supervisor gossip is negatively associated with employee job engagement.

\section{Employee Job Engagement and Job Performance.}

There is a general believe that employee engagement has positive consequences to an organization, especially with regards to business performance(Harter et al., 2002). Employee engagement has been found to influence individual performance as well as that of the business unit where that employee works, and ultimately that of the whole organization(Harter et al., 2002). That notwithstanding, employee job engagement tends to attract more attention to business researchers than organizational engagement(Saks, 2006). Since employee job engagement tends to be related to individuals' attitudes, behaviors, and intentions(Kahn, 1990), its ultimate outcomes will most likely affect one's job performance as appraised by supervisor. Evidence indicates that employees' job engagement results to positive job outcomes. Schaufeli and Bakker (2004), found that job engagement increases job fulfilment of new and unexperienced employees, as well as improving their work related positive job experiences and state of mind. These positive job experiences are related to employee job satisfaction, self fulfilment, and positive work effect (Brady et al., 2017).

Further Siddiqui et al. (2004), notes that engaged employees are likely experience greater job and organizational attachment, leading to less turnover intentions. Evidence has it that highly engaged employees will have a higher organizational citizen behavior(Saks, 2006), experiences high job satisfaction and commitment, and of less burn out(Maslach et al., 2001). Employee state of mind and positive work related experiences are higher among employees who are perceived to be highly engaged at work. Subsequently, this has been linked to higher job performance and effectiveness (Schaufeli \& Bakker, 2004). Based on these evidences, this study postulates that highly engaged employees will have higher attachment and commitment to their job roles, which will translate to high job performance.

H3: Job engagement of public sector employees is positively associated with employee job performance.

\section{Mediation Role of Employee Engagement}


Evidence alludes that employee job engagement is associated to work outcomes (Saks, 2006). However, the work outcomes may vary from private sector to public sector. Many organizational studies intimate that private sector is inclined towards profit, whereas public sector is inclined towards quality service delivery(Kompaso \& Sridevi, 2010). However in both cases, employee engagement is a necessary impetus in the realization of organizational goals and objectives(Ibrahim \& Al Falasi, 2014). The research model by Maslach et al. (2001) treats engagement as a mediator between the six work conditions and various job outcomes like burnout, increased task withdrawal, decline in job satisfaction, and reduced performance. Schaufeli and Bakker (2004), found that engagement was negatively related to turnover intention, and that it mediated the relationship between job resources and turnover intention. This study however postulated the mediation effect of employee job engagement in the context of social exchange theory (SET), which argues that obligations between parties are generated through a series of interactions between those parties who are in a state of reciprocal interdependence. This reciprocal interdependence is pegged on trust and mutual commitment(Cropanzano \& Mitchell, 2005). Therefore, based on the SET, the present study therefore hypothesized that positive supervisor gossip concerning employee performance of tasks will confer obligations to employees to be absorbed to their jobs in order to achieve the anticipated performance which will elicit similar future positive gossip from the same supervisor. Conversely, negative supervisor gossip, will leave employees with no debt to repay which will make them less absorbed to their job roles. Therefore, the final hypothesis on employee job engagement as a mediator between supervisor gossip and job performance were framed as follows:

H4. Positive supervisor gossip enhances employee job engagement which leads to an increase in employee job performance.

H5. Negative supervisor gossip diminishes employee job engagement which leads to decline in their job performance.

\section{Research and Methods}

\section{Sample and Procedures}

This study aimed at establishing the effect of supervisor gossip on employee workplace engagement and job performance. The study utilized dyadic research design and a semi structured questionnaire for data collection. Data was collected from a sample of 267 employees and 42 supervisors, out of a total of 2200 employees and 94 supervisors of the Government Municipal Council of Kwa- Zulu Natal province, South Africa. Proportionate stratified sampling was used so as ensure the sample was a representative of different departments in the municipality. To reduce the variance associated with common method of data collection(CMV), three waves of data collection $\left(X_{1}, X_{2}\right.$, and $X_{3}$, ) were carried out in line with the guidelines of Chang, van Witteloostuijn, and Eden (2010). All ethical standards during data collection were adhered to. Both employees and supervisors were explained to concerning the purpose of the study and how data collection procedure would take place. The first survey wave $\left(X_{1}\right)$ that was carried out on the sampled employees focused on their demographics and rated their perception of supervisor positive gossip and job engagement.

The second wave $\left(\mathrm{X}_{2}\right)$, was carried out after one month, and focused on the same employees' perceptions of supervisor negative workplace gossip and their job engagement. The third wave $\left(X_{3}\right)$, was also carried out after a month and focused on the 62 supervisors rating their respective employee on their job performance in the previous financial year. We made sure that only supervisors whose employees returned questionnaires in wave $X_{1}$ and wave $X_{2}$ participated in the study. Only 238 questionnaires were successfully completed for wave one $\left(X_{1}\right)$, and 238 for wave two $\left(X_{2}\right)$ representing about $95 \%$ response rate. 58 questionnaires were completed by the supervisors representing about $93 \%$ response rate. After matching wave one, two, and three, 228 questionnaires were successfully matched representing about $85 \%$ complete supervisorsubordinate questionnaire. Out of 228 sampled employees, $61 \%$ were males, while $39 \%$ were female with an average tenure in the municipality of 7.6 years. The average age of the employees was 32.65 years, while that of the supervisor was 34.96 years.

\section{Measures}


Various measures were used to measure supervisor gossip, employee job engagement and job performance. The questionnaire was piloted amongst eight employees and three supervisors in four departments (Fire emergency, underground packing, road-side business licensing, and public complaint section). This sample was for the purposes of ascertaining construct validity of the questionnaire were not included in the final analysis (Chang et al., 2010).

\section{Superior Positive and Negative Gossip}

Supervisor gossip was measured as perceived by the target. Supervisor positive gossip was measured by the three-item scale developed by Chandra and Robinson (2009). The responses were made on a Likert scale ranging from 1 (never) to 5 (daily). The items included "In the last six months, my supervisor commented negative things about me in the workplace," my supervisor spread damaging information about me in the workplace", and 'my supervisor made unfavorable remarks about my work in this organization'. Minor adjustments were made to the scales in line with the objectives of the study". ( $\alpha=.76$ )

\section{Employee job engagement}

Employee Job Engagement was assessed using the Utrecht Work Engagement Scale(Schaufeli \& Bakker, 2003). A 17-item questionnaire on a 6-point Likert-type scale was used. The items ranged from 1 (strongly disagree) to 6 (strongly agree), e.g.: "I'm immersed in my work". Of all the 17 job engagement items, 12 items loaded above 0.70 with cross-factor loadings of less than 0.20 , while five items did not. The five items were ultimately removed from the job engagement scale resulting in a five-item scale $(\alpha=.84)$

\section{Employee job performance.}

Employee job performance was measured using a generic version of employee work performance scale (IWP)(Campbell, McHenry, \& Wise, 1990) developed by Koopmans et al. (2012). After adoption of this scale, employee job performance was depicted by four dimensions: task performance (4 items), adaptive performance ( 3 items), contextual performance ( 3 items), and counterproductive work behavior ( 3 items). The study picked items from the list of IWPQ that were more relevant to the scope of the study. The Cronbach alpha for each dimension was above 0.7 , and as such a composite variable representing employee job performance was generated from the four constructs.

\section{Control Variables}

Four demographic variables namely age of employees/supervisor, gender, tenure and education level were included in the model in line with previous studies on employee engagement and performance(Robinson et al., 2004; Saks, 2006). Gender was dummy-coded as 0 for male and 1 for female, while Age and organizational tenure were self-reported in years.

\section{Results}

\section{Preliminary Analysis}

Since the data was collected from the same source, the common method variance (CMV) was performed using Harman Single-factor test. Only one factor emerged out of the test explaining $26.5 \%$ of variance indicating that $\mathrm{CMV}$ was not a problem. Adequacy of sample size was ascertained using $\mathrm{KMO}$ and a value of 0.67 indicated that the sample size was adequate. Table I below represents the means, standard deviations, correlations and reliabilities, of the research variables.

Table 1: Correlations, scale Reliabilities, Mean and Standard Deviations.

\begin{tabular}{|l|l|l|l|l|l|l|l|l|l|l|l|}
\hline & & Mean & SD & 1 & 2 & 3 & 4 & 5 & 6 & 7 & 8 \\
\hline 1 & Age & 32.65 & 6.35 & & & & & & & & \\
\hline 2 & Gender & 0.43 & 0.48 & 0.16 & & & & & & & \\
\hline 3 & Tenure & 7.60 & 2.46 & -0.09 & 0.02 & & & & & & \\
\hline 4 & Education & 2.34 & 0.56 & -0.06 & -.02 & -0.01 & & & & & \\
\hline 5 & Positive Gossip & 5.36 & 0.75 & -0.16 & 0.22 & $0.22^{*}$ & $0.16^{*}$ & $\mathbf{( 0 . 7 9 )}$ & & & \\
\hline 6 & Negative Gossip & 3.58 & 0.84 & 0.28 & -0.08 & 0.02 & -0.08 & 0.01 & $\mathbf{( 0 . 7 6 )}$ & & \\
\hline
\end{tabular}


Dlamani et al. / International Journal of Research in Business and Social Science,

Vol 7 No 4, 2018 ISSN: 2147-4486

\begin{tabular}{|l|l|l|l|l|l|l|l|l|l|l|l|}
\hline 7 & $\begin{array}{l}\text { Job } \\
\text { Engagement }\end{array}$ & 4.68 & 0.68 & 0.08 & -0.02 & 0.04 & $0.26^{*}$ & $0.36^{* *}$ & -0.41 & $\mathbf{( 0 . 8 6 )}$ & \\
\hline 8 & $\begin{array}{l}\text { Job } \\
\text { performance }\end{array}$ & 3.96 & 0.84 & 0.06 & -0.06 & 0.03 & $0.32^{*}$ & $0.21^{* *}$ & $-0.38^{* *}$ & $0.36^{* *}$ & $\mathbf{( 0 . 8 8 )}$ \\
\hline
\end{tabular}

Note: Diagonal values represent Cronbach's alpha value for each scale. Gender is coded $0=$ male and $1=$ female. $N=238,{ }^{*} \mathrm{P} \leq 0.05 ;{ }^{* *} \mathrm{P} \leq 0.01$ (two-tailed).

From the table 1 above, that positive supervisor gossip was positively correlated with employee job engagement $(r=0.32, p=0.01)$, but negative supervisor gossip was negatively correlated with job engagement $(r=-0.41, p=0.24)$. Employee job engagement was positively correlated with employee job performance $(r=$ $0.36, p=0.01$ ).

In all the four constructs, construct reliability $C R$ ) values were above 0.75 , indicating a good construct validity.

\section{Validity issues}

To ascertain the extent to which items assessed the intended construct rather than other construct(Holden \& Jackson, 1979), substantive validity was carried out on the four constructs of the study using a substantive validity item-sort task put forward by Anderson and Gerbing (1991). All items that were substantially valid were retained, while those that were not were left out. Subsequently, a confirmatory factor analysis was carried out to ascertain convergent and construct validity of the variables. To achieve this, a four factor hypothetical model (consisting of supervisor positive gossip, supervisor negative gossip, employee job engagement, and employee job performance) was used as a baseline and tested for item parceling for fit indices in line with the homogeneous strategy(Little, Cunningham, Shahar, \& Widaman, 2002). The four factor model fit indices revealed an adequate model fit $\left(X^{2}=275.31(129), p=0.01\right.$, Tucker-Lewis index (TLI) $=0.95$, Comparative Fit Index $(\mathrm{CFI})=0.96$, and Root Mean Square Error of Approximation (RMSEA) $=0.06$ ). The standardized coefficients from items to factors also ranged from 0.71 to 0.92 , and were all statistically significant $(p=0.001)$. Additionally, discriminant validity of the four constructs was tested by contrasting the baseline model against the other three alternative models, and the results are as shown below in table 2 below:

Table 2: Comparison of Model Fitness.

\begin{tabular}{|c|c|c|c|c|c|c|}
\hline Model & $\begin{array}{l}\text { No of } \\
\text { Factors }\end{array}$ & $x^{2(d f)}$ & $\Delta \mathrm{X} 2(\mathrm{df})$ & RMSEA & TLI & CFI \\
\hline Hypothetical model & 4 & 275.31(129) & & 0.06 & 0.95 & 0.96 \\
\hline Model 1 & 3 & $586.95(133)$ & $411.62(3)^{* * *}$ & 0.15 & 0.78 & 0.82 \\
\hline Model 2 & 3 & $560.36(133)$ & $392.91(3) * * *$ & 0.16 & 0.79 & 0.86 \\
\hline Model 3 & 2 & $835.32(135)$ & $596.49(5)^{* * *}$ & 0.21 & 0.56 & 0.68 \\
\hline Model 4 & 1 & 1234.12(136) & $1041.17(6)$ *** & 0.32 & 0.18 & 0.31 \\
\hline
\end{tabular}

Notes: Hypothetical model: positive supervisor gossip, negative supervisor gossip, Job engagement, and job performance; Model 1: positive supervisor gossip and negative supervisor gossip were merged into one factor; Model 2: Job engagement and employee job performance were merged into one factor; Model 3: positive supervisor gossip, negative supervisor gossip, and job engagement were merged into one factor; Model 4: all variables were merged into one factor. ${ }^{* \star *} p=0.001$.

From the results in Table 2 above, the hypothetical model (base model) had a significantly better fit, than the rest of the models. Additionally, the $x 2$ changes between the base model and the rest of the models were significant thus the hypothetical model was adopted for the analysis of the constructs. With regards to construct validity, the AVE values for all the four models was above 0.5 , indicating a high construct validity for the constructs.

\section{Hypothesis Testing}

The hypothetical model having provided the best fit, was utilized to test the hypothesis by constructing a latent structural equation model in Amos 22(Figure 1). We predicted a positive relationship between positive superior gossip and job engagement ( $\mathrm{H} 1)$, and Negative relationship between negative superior gossip and job engagement $(\mathrm{H} 2)$. As shown in figure 1 below, the coefficient for the path from positive superior gossip to employee job engagement was positive and significant $(\beta=0.28, p \leq 0.001)$, whereas that from negative 
superior gossip to employee job engagement was negative but insignificant $(\beta=-0.38, p \geq 0.001)$, hence $H_{1}$ was supported while $\mathrm{H}_{2}$ was not supported. This implied that increase in positive superior gossip will increase employee job engagement, whereas increase in negative superior gossip will either positively or negatively influence employee job engagement. We also predicted a positive relationship between employee job engagement and job performance $(\mathrm{H} 3)$. From figure 1 , the coefficient for the path from employee job engagement to job performance was positive and significant $(\beta=-0.34, p \leq 0.001)$, hence $H 3$ was supported.

The last research hypothesis predicted that the relationship between positive superior gossip and employee job performance $(\mathrm{H} 4)$, and that the relationship between negative superior gossip and employee job performance (H5), were both mediated by employee job engagement. The mediation effect of job engagement (Fig 1), was tested through the bootstrapping approach. In this approach, the indirect effect of positive superior gossip on job performance through job engagement, and that of negative superior gossip on job performance through job engagement were estimated. The indirect effect estimation was carried out while controlling for employees age, gender, tenure, and level of education. The mediation analysis revealed a positive and significant indirect effect of supervisor positive gossip on employee job performance through job engagement (indirect effect $=0.11, p<0.05$ ), and a positive but insignificant mediation effect of negative supervisor gossip on job performance through job engagement (indirect effect $=0.03, p>.05$ ). Consequently, $\mathrm{H} 4$ was supported while H5 was not. The bootstrapping model was adequately fit $(x 2=218.27(130), p=0.001$, RMSEA $=0.07$,

$\mathrm{CFI}=0.94, \mathrm{TLI}=0.92)$. Further, other parameters were estimated from the partial mediation model including those of positive and negative superior gossip on job engagement, and that of job engagement on job performance and they were found to be closely identical to the hypothetical model. Evidently, the coefficients of positive and negative supervisor gossip had nonsignificant direct effects on employee job performance ( $\beta=0.06$ and $\beta=-0.06$, respectively), and this ultimately demonstrated that employee job engagement fully mediated the relationship between supervisor gossip and employee job engagement.

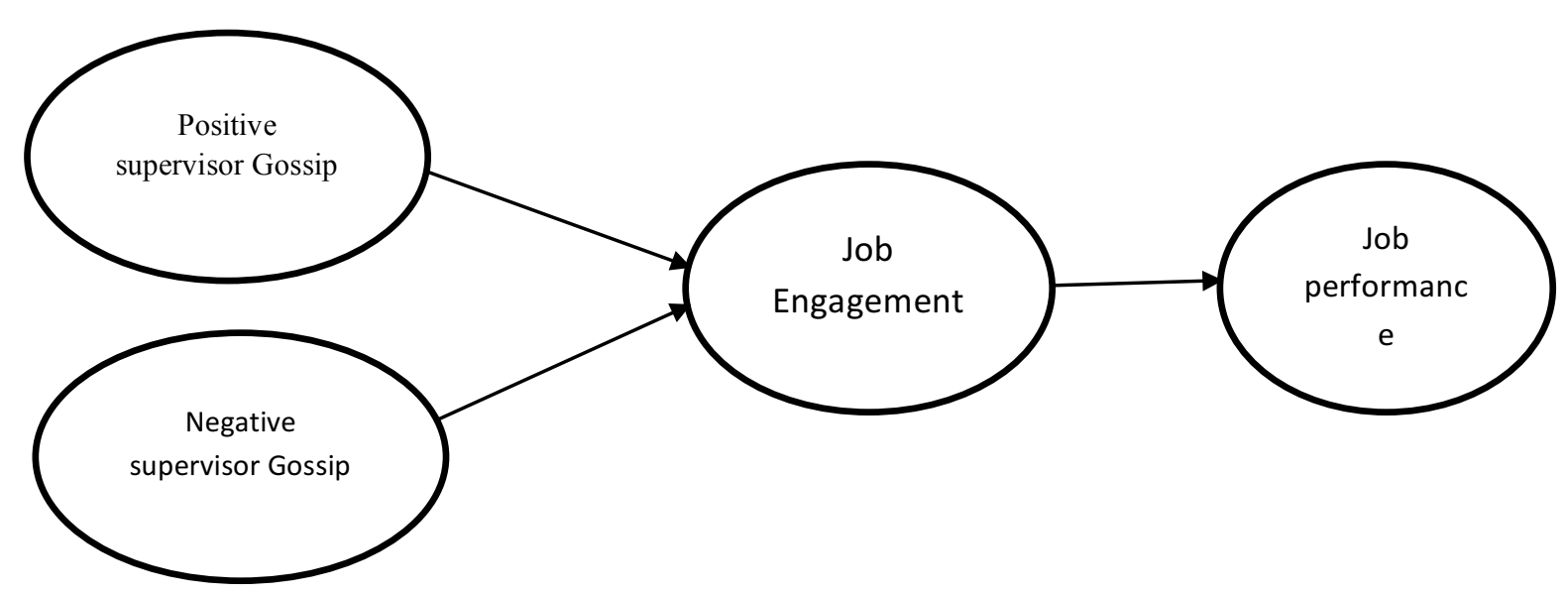

Figure 1: The Hypothetical model with standardized parameter estimates.

$\mathrm{N}=228, \mathrm{X} 2=275.31$ (129); $\mathrm{p}<0.001 ; \mathrm{CFI}=0.96 ; \mathrm{TLI}=0.95 ; \mathrm{RMSEA}=0.06 .{ }^{* * *} \mathrm{p}<0.001$

The bootstrapping mediation results implied that positive supervisor gossip had a positive influence on employee job performance, through positive job engagement, while negative supervisor gossip had both negative and positive effects on job engagement, which only caused positive, but insignificant effects on job performance.

\section{Discussions}

Workplace gossip has received a lot of attention by practitioners and consultants in organizational behavior, organization psychology, and other related disciplines. However, scholarly work on supervisor gossip and employee outcomes especially in the public sector remains scanty. This study sought to establish the effect of positive and negative superior gossip on employee job performance, while treating employee job 
engagement as a mediator. We hypothesized that positive superior gossip will positively influence employee job engagement, which will in turn improve their job performance, while negative superior gossip will negatively influence employee job engagement which will in turn lead to decline in their job performance. We made two key findings: Firstly, positive supervisor gossip positively influenced employ engagement, while negative supervisor gossip had a negative, but insignificant effect on employee engagement; secondly, employee job engagement mediated the effects of both positive but not negative superior gossip, on employee job performance. Job engagement was preferred to organizational engagement as psychological construct to be related to workplace place gossip and individual employee job performance in the public set up. Negative supervisor gossip could have elicited both negative and positive effects on employee behaviors as supported by previous studies(Wu et al., 2016). Finally, we allude that positive supervisor gossip effects on employee engagement are outcomes of social exchange between the supervisor and employees, in that employees who experience positive supervisor gossip are more likely to reciprocate with greater job engagement than those who experienced negative supervisor gossip. However, since the antecedents of job engagement are many(Saks, 2006), its effect on job performance was high making it a suitable mediator for positive superior gossip than negative supervisor gossip.

\section{Implications of the Study}

There are numerous calls to expand literature on workplace gossip(Kuo et al., 2015; Kuo et al., 2018). This study suggests that managerial workplace gossip and employee outcomes in public sector entities is one of such responses. Despite controlling for tenure and education level of employees, the study implied that workplace supervisor gossip had monumental effects on employee engagement and job performance in many ways. Firstly, the theoretical postulate of Kuo et al. (2015) on leadership and the power relations between the gossiper and its subordinates reinforces the social exchange theory cultivated by this study where we argue that positive gossip from departmental supervisors in the public sector, confers reciprocal obligation to employees which culminates to high levels of workplace job engagement and ultimate performance. Secondly, since leadership outcomes is about communication, this study poses that communication of negative supervisor gossip may serve as a form of extrinsic motivation to employees through sanctions which may increase job engagement and ultimate performance. Practically, both negative and positive superior gossip may improve employee effectiveness. Therefore managers should understand the importance of effective social exchange between them and subordinates in form of gossip so as to enhance better employee engagement.

\section{Conclusions}

This study concludes that workplace supervisor gossip is an important aspect that should be awarded a lot of scholarly attention in the field or organization management. The findings from this study that both positive and negative supervisor gossip positively influences employee job engagement and ultimate job performance, implies that gossip is quite instrumental in organizational communication and therefore managers and supervisors should harness positive outcomes associated with it. Lastly, as an emerging field in organization management, it should further be explored within psychological paradigms.

The study assumed the causal relationship that may exist between various constructs in the study as well as employees' aspects of self-regulation which could influence their response to gossip. In addition to selfregulation, the proposition by this study that negative supervisor gossip may act as indirect communication tool maybe have limitations due to existence of unethical or abusive negative supervisor gossip especially among employees with job security. Secondly, other than controlling for tenure of since there are many antecedents of employee engagement (both organizational and job engagement) there could exist methodological biases arising from clustered nature of organizational data whose variances could be disentangled by empirical investigation through multilevel modelling with fixed effects.

\section{Acknowledgement}

This study was self-funded. Ethical approval for this study was granted from the Huazhong University of Science and Technology school of Management as well as the South African Research Council. All 
procedures performed in this study involving human participants were in accordance with the ethical standards of the institution and relevant permission was granted before collecting data from the participants. Informed consent was obtained from all the participants in this study. All the authors declare that they have no conflict of interest.

\section{References}

Anderson, J. C., \& Gerbing, D. W. (1991). Predicting the performance of measures in a confirmatory factor analysis with a pretest assessment of their substantive validities. Journal of applied Psychology, 76(5), 732.

Baumeister, R. F., Zhang, L., \& Vohs, K. D. (2004). Gossip as cultural learning. Review of general psychology, 8(2), 111.

Beersma, B., \& Van Kleef, G. A. (2012). Why people gossip: An empirical analysis of social motives, antecedents, and consequences. Journal of Applied Social Psychology, 42(11), 2640-2670.

Bosson, J. K., Johnson, A. B., Niederhoffer, K., \& Swann, W. B. (2006). Interpersonal chemistry through negativity: Bonding by sharing negative attitudes about others. Personal Relationships, 13(2), 135150.

Brady, D. L., Brown, D. J., \& Liang, L. H. (2017). Moving beyond assumptions of deviance: The reconceptualization and measurement of workplace gossip. Journal of applied Psychology, 102(1), 1.

Campbell, J. P., McHenry, J. J., \& Wise, L. L. (1990). Modeling job performance in a population of jobs. Personnel Psychology, 43(2), 313-575.

Chandra, G., \& Robinson, S. (2009). They're talking about me again: The negative impact of being the target of gossip. Paper presented at the Academy of Management Annual Meeting, Chicago, Illinois, USA.

Chang, S.-J., van Witteloostuijn, A., \& Eden, L. (2010). From the Editors: Common method variance in international business research. Journal of International Business Studies, 41(2), 178-184. doi: $10.1057 /$ jibs.2009.88

Cropanzano, R., \& Mitchell, M. S. (2005). Social exchange theory: An interdisciplinary review. Journal of Management, 31(6), 874-900.

Dunbar, R. I. (2004). Gossip in evolutionary perspective. Review of general psychology, 8(2), 100.

Harter, J. K., Schmidt, F. L., \& Hayes, T. L. (2002). Business-unit-level relationship between employee satisfaction, employee engagement, and business outcomes: a meta-analysis. Journal of applied Psychology, 87(2), 268.

Holden, R. R., \& Jackson, D. N. (1979). Item subtlety and face validity in personality assessment. Journal of Consulting and Clinical Psychology, 47(3), 459.

Ibrahim, M., \& Al Falasi, S. (2014). Employee loyalty and engagement in UAE public sector. Employee Relations, 36(5), 562-582.

Kahn, W. A. (1990). Psychological conditions of personal engagement and disengagement at work. Academy of Management Journal, 33(4), 692-724.

Kompaso, S. M., \& Sridevi, M. S. (2010). Employee engagement: The key to improving performance. International journal of business and management, 5(12), 89.

Koopmans, L., Bernaards, C., Hildebrandt, V., van Buuren, S., van der Beek, A. J., \& de Vet, H. C. (2012). Development of an individual work performance questionnaire. International Journal of Productivity and Performance Management, 62(1), 6-28.

Kuo, C.-C., Chang, K., Quinton, S., Lu, C.-Y., \& Lee, I. (2015). Gossip in the workplace and the implications for HR management: A study of gossip and its relationship to employee cynicism. The International Journal of Human Resource Management, 26(18), 2288-2307.

Kuo, C.-C., Wu, C.-Y., \& Lin, C.-W. (2018). Supervisor workplace gossip and its impact on employees. Journal of managerial psychology, 33(1), 93-105.

Kurland, N. B., \& Pelled, L. H. (2000). Passing the word: Toward a model of gossip and power in the workplace. Academy of management review, 25(2), 428-438.

Little, T. D., Cunningham, W. A., Shahar, G., \& Widaman, K. F. (2002). To parcel or not to parcel: Exploring the question, weighing the merits. Structural equation modeling, 9(2), 151-173. 
Maslach, C., Schaufeli, W. B., \& Leiter, M. P. (2001). Job burnout. Annual review of psychology, 52(1), 397422.

May, D. R., Gilson, R. L., \& Harter, L. M. (2004). The psychological conditions of meaningfulness, safety and availability and the engagement of the human spirit at work. Journal of occupational and organizational psychology, 77(1), 11-37.

Mills, C. (2010). Experiencing gossip: The foundations for a theory of embedded organizational gossip. Group \& Organization Management, 35(2), 213-240.

Restubog, S. L. D., Bordia, P., Tang, R. L., \& Krebs, S. A. (2010). Investigating the moderating effects of leader-member exchange in the psychological contract breach-employee performance relationship: A test of two competing perspectives. British journal of management, 21(2), 422-437.

Robinson, D., Perryman, S., \& Hayday, S. (2004). The drivers of employee engagement. Report-Institute for Employment Studies.

Rothbard, N. P. (2001). Enriching or depleting? The dynamics of engagement in work and family roles. Administrative science quarterly, 46(4), 655-684.

Saks, A. M. (2006). Antecedents and consequences of employee engagement. Journal of managerial psychology, 21(7), 600-619.

Schaufeli, W. B., \& Bakker, A. B. (2003). Utrecht work engagement scale: Preliminary manual. Occupational Health Psychology Unit, Utrecht University, Utrecht, 26.

Schaufeli, W. B., \& Bakker, A. B. (2004). Job demands, job resources, and their relationship with burnout and engagement: A multi-sample study. Journal of organizational Behavior, 25(3), 293-315.

Siddiqui, S. M., Sauer, R. T., \& Baker, T. A. (2004). Role of the processing pore of the ClpX AAA+ ATPase in the recognition and engagement of specific protein substrates. Genes \& development, 18(4), 369-374.

Traylor, T. (2008). Employee Performance Evaluation (EPE): The Good, The Bad, and The Ugly. City.

Utaminingsih, R., \& Purnomo, R. (2017). Antecedents and Consequences of Employee Engagement. Jurnal Akuntansi Manajemen dan Ekonomi, 19(2), 53-60.

Wu, L.-Z., Birtch, T. A., Chiang, F. F., \& Zhang, H. (2018). Perceptions of negative workplace gossip: A selfconsistency theory framework. Journal of Management, 44(5), 1873-1898.

Wu, L.-Z., Birtch, T. A., Chiang, F. F. T., \& Zhang, H. (2016). Perceptions of Negative Workplace Gossip: A Self-Consistency Theory Framework. Journal of Management, 44(5), 1873-1898. doi: 10.1177/0149206316632057 